Article

\title{
Evaluation of the Individual and Combined Toxicity of Fumonisin Mycotoxins in Human Gastric Epithelial Cells
}

\author{
Song Yu, Bingxuan Jia, Na Liu, Dianzhen Yu and Aibo Wu*(i) \\ SIBS-UGENT-SJTU Joint Laboratory of Mycotoxin Research, CAS Key Laboratory of Nutrition, \\ Metabolism and Food Safety, Shanghai Institute of Nutrition and Health, \\ University of Chinese Academy of Sciences, Chinese Academy of Sciences, Shanghai 200031, China; \\ syu@sibs.ac.cn (S.Y.); jiabingxuan2017@sibs.ac.cn (B.J.); liuna@sibs.ac.cn (N.L.); dzyu@sibs.ac.cn (D.Y.) \\ * Correspondence: abwu@sibs.ac.cn; Tel.: +86-21-54920716
}

Received: 23 July 2020; Accepted: 14 August 2020; Published: 18 August 2020

\begin{abstract}
Fumonisin contaminates food and feed extensively throughout the world, causing chronic and acute toxicity in human and animals. Currently, studies on the toxicology of fumonisins mainly focus on fumonisin B1 (FB1). Considering that FB1, fumonisin B2 (FB2) and fumonisin B3 (FB3) could coexist in food and feed, a study regarding a single toxin, FB1, may not completely reflect the toxicity of fumonisin. The gastrointestinal tract is usually exposed to these dietary toxins. In our study, the human gastric epithelial cell line (GES-1) was used as in vitro model to evaluate the toxicity of fumonisin. Firstly, we found that they could cause a decrease in cell viability, and increase in membrane leakage, cell death and the induction of expression of markers for endoplasmic reticulum (ER) stress. Their toxicity potency rank is FB1 $>$ FB2 $>>$ FB3. The results also showed that the synergistic effect appeared in the combinations of FB1 + FB2 and FB1 + FB3. Nevertheless, the combinations of $\mathrm{FB} 2+\mathrm{FB} 3$ and FB1 + FB2 + FB3 showed a synergistic effect at low concentration and an antagonistic effect at high concentration. We also found that myriocin (ISP-1) could alleviate the cytotoxicity induced by fumonisin in GES-1 cells. Finally, this study may help to determine or optimize the legal limits and risk assessment method of mycotoxins in food and feed and provide a potential method to block the fumonisin toxicity.
\end{abstract}

Keywords: fumonisins; cytotoxicity; ER stress; risk prioritizing; combined toxicity

\section{Introduction}

As akin natural contaminators produced by Fusarium, Fusarium mycotoxins are not necessary for fungal growth, while they can fertilize the process of crop infection and cause plant diseases [1-3]. According to the Food and Agriculture Organization of the United Nations (FAO), mycotoxin contamination is affecting the entire food chain and causes more than $25 \%$ cereal crops loss each year [4]. Fumonisin is a highly toxic low molecular weight fusarium mycotoxin, which is produced by a number of fusarium species, predominantly Fusarium verticillioides and Fusarium proliferatum $[5,6]$. The chemical structure of 28 kinds of fumonisins have been identified by now, which can be divided into A, B, C and P. Among them, fumonisin B1 (FB1), fumonisin B2 (FB2) and fumonisin B3 (FB3) are the main forms. Their structure is characterized by 20-carbon aminopolyhydroxy alkyl chain esterified with two molecules of tricarboxylic acid (-TCA), but they have different amounts of hydroxyl group $(-\mathrm{OH})$ and the positions of the hydroxyl group $(-\mathrm{OH})$ are different as well (Figure 1) [7]. They have often been examined in food and feed all over the world, especially in corn and the products made of corn-flavored ingredients [8,9]. In 2001, a survey of mycotoxin contamination on 4327 grain samples 
worldwide showed that for major fumonisin B (FBs) positive rates were approximately $27 \%, 51 \%$, $58 \%, 56 \%$, and 55\%, respectively, in North America, Central Europe, Africa, South Asia, and Southeast Asia. The prevalence in South America was the highest, with a positive rate of $76 \%$ (average level of $1.50 \mathrm{mg} / \mathrm{kg}$ ) [10]. The content of FB contaminators in compound feed and feed ingredients was $93.33 \%$ and $83.33 \%$. Most poultry broiler (early) feeds were seriously contaminated by FBs, and the highest detected level in one feed being $12.82 \mathrm{mg} / \mathrm{kg}$ in Korea in 2012 [11]. In 2014, the incidence of FB1, FB2 and FB3 in corn products (corn flakes, corn meal and grits) in Shandong province was $98.10 \%$, and the highest levels were 5046, 1350 and $712.10 \mu \mathrm{g} / \mathrm{kg}$, respectively [12]. Because of the characteristics of this toxin such as its thermal stability and corrosion resistance, they are difficult to eliminate [13]. Once they are absorbed by humans and animals through the food chain, they will threaten human and animal health and cause serious economic losses [14].
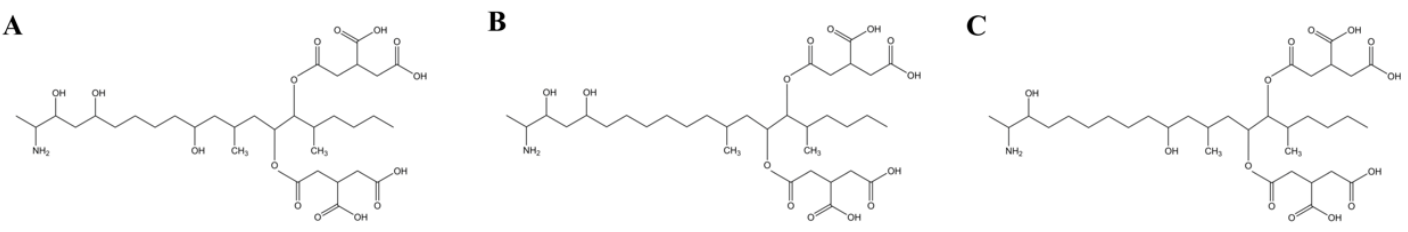

Figure 1. The chemical structure of major fumonisin B: (A) fumonisin B1; (B) fumonisin B2; and (C) fumonisin B3.

Fumonisin B1 (FB1) is the most prevalent member of fumonisin and causes diverse toxic effects in humans and domestic animals, including neurotoxicity, hepatotoxicity and carcinogenesis, resulting from oxidative stress, apoptosis, necrosis and alterations in cell proliferation and differentiation [15-19]. Ceramide synthase catalyzes the formation of ceramide from sphinganine and acyl-CoA as substrates. Several lines of evidence indicate that the toxicity of FB1 caused by the aminopentol backbone competes against the binding of the sphingoid base substrate, whereas the tricarballylic acids interfere with the binding of the fatty acyl-CoA, the accumulation of free sphingoid bases via the inhibition of ceramide synthase leads to the disruption of the sphingolipid metabolism. FB1 can be converted to N-acylation FB1 by ceramide synthase [20-23]. However, there are limited studies on the toxicity of FB2 and FB3, and no studies have assessed the toxicity of fumonisin B (FBs) mixtures. It is worth mentioning that the current safety limit standards and regulatory formulations of mycotoxins mainly use the toxicology data as references. With the development of toxicology technology, only the consideration of toxicity from one single mycotoxin but not the combined effects (synergistic, additive, and antagonistic) of the mycotoxin mixtures did not obviously reflect the real toxicity of mycotoxins [24-26]. However, the data focused on the combination toxicity of mycotoxin are limited. Many investigative studies have shown that the presence of fumonisin family mycotoxins in food and feed is always spatiotemporally synchronized [27-29]. Therefore, the evaluation of the toxicological effects of mycotoxin interactions is important for accurately calculating the health risks of such mycotoxin contaminations and formulating relevant safety regulations.

The gastrointestinal tract is often an important target for first exposure to these dietary toxins $[30,31]$. It is reported that FB1 can affect the health of the gastrointestinal tract (GIT) in animals [32,33]. Nevertheless, the effect of fumonisin on the human gastrointestinal tract was poorly understood. In order to obey the rules of 3R, the human gastric epithelial cell line (GES-1) was used in this study as an in vitro model to evaluate the toxicity of FBs, a class of common fumonisins. Our previous research indicated that the cytotoxicity induced by FB1 was not obvious at $24 \mathrm{~h}$, while all groups $(2.5-40 \mu \mathrm{M})$ could significantly induce cytotoxicity at $48 \mathrm{~h}$ [10]. Therefore, this experiment chose the timepoint of $48 \mathrm{~h}$ as the exposure time. First, we assessed the effects of FBs on cell viability, membrane leakage, cell death and the expression levels of endoplasmic reticulum (ER) stress markers to evaluate the rank of the toxicity risk. Furthermore, we assessed the combined toxicity of the fumonisin mixtures and the remission effect of myriocin (ISP-1). These data provide a new reference for establishing and 
optimizing the law and regulation regarding the safety of mycotoxins and a novel channel to block FBs toxicity.

\section{Results}

\subsection{FBs Inhibited Cell Proliferation and Increased Lactic Dehydrogenase Levels in GES-1 Cells}

Cell viability and cell membrane leakage are two independent indicators for evaluating cytotoxicity. We used Cell Counting Kit-8 (CCK-8) (DOJINDO) and Cytotoxicity Lactic Dehydrogenase (LDH) assay (DOJINDO) to detect the cytotoxicity of FBs in the human gastric epithelial cell line (GES-1) (Beijing Beina Chuanglian Biotechnology Institute). As shown in Figure 2, the cell viability rate decreased and LDH increased in a dose-dependent manner in the presence of 2.5-40 $\mu \mathrm{M}$ FB1. After $48 \mathrm{~h}$ of exposure to FBs, the GES- 1 cells had the lowest viability level under $40 \mu \mathrm{M}$ FBs. The inhibition rates of $40 \mu \mathrm{M}$ FB1, FB2 and FB3 were $69.16 \%, 64.32 \%$ and $54.60 \%$, respectively (Figure 2A). Simultaneously, when the GES-1 cells were treated with $5 \mu \mathrm{M}$ FB1 or FB2 for $48 \mathrm{~h}$, the LDH leakage rates were significantly different from the rate in the control group; however, FB3 did not cause a significant increase in LDH. The LDH leakage rate reached the highest level, compared with the control group at a $40 \mu \mathrm{M}$ dose after $48 \mathrm{~h}$ (Figure 2B). The cytotoxicity of FB1 and FB2 was significantly higher than that of FB3.

A

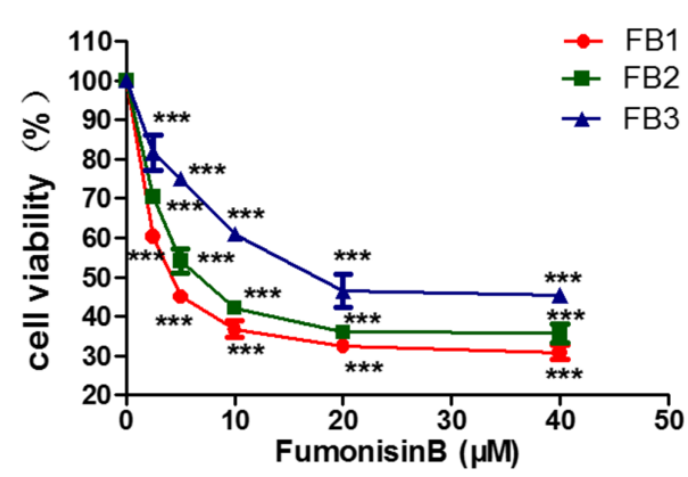

B

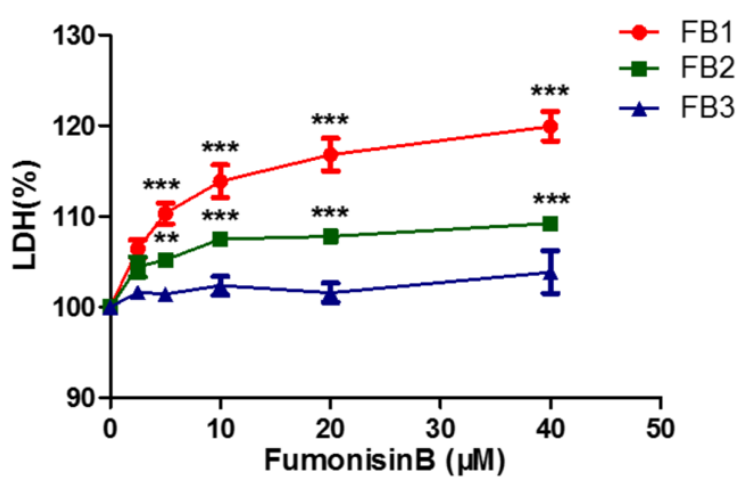

Figure 2. The cytotoxicity of fumonisins B (FBs) on the human gastric epithelial cell line (GES-1) was shown to decrease the cell viability rate and increase the LDH leakage rate. (A) Cell viability was assessed by the cell count kit-8 cell proliferation assay. (B) Cell membrane integrity was determined by detecting the LDH leakage from the cell media using a cytotoxicity LDH detection kit. These data represented the mean \pm SEM of the three individual experiments $\left(^{* *} p<0.01,{ }^{* * *} p<0.001\right.$, analysis of variance (ANOVA) test).

\subsection{FBs Induced Cell Death in GES-1 Cells}

We further investigated the effect of FBs on GES-1 cell death. Dead cells could be marked with Annexin V-fluoresceine isothiocyanate/propidium iodide (Annexin V-FITC/PI) dye. Flow cytometry analysis was used to quantify the cell death rate in the total cell population. After incubation with FBs $(10,20$ and $40 \mu \mathrm{M})$ for $48 \mathrm{~h}$, the cell death rates were obviously increased in the FBs treatment groups, compared with the control group (Figure $3 \mathrm{~A}, \mathrm{~B}$ ). The main form of cell death was necrosis. The highest mortalities were $48.44 \%, 34.66 \%$ and $27.37 \%$ in the FB1, FB2 and FB3 group, respectively. FB1 was more lethal than FB2 and FB3. 


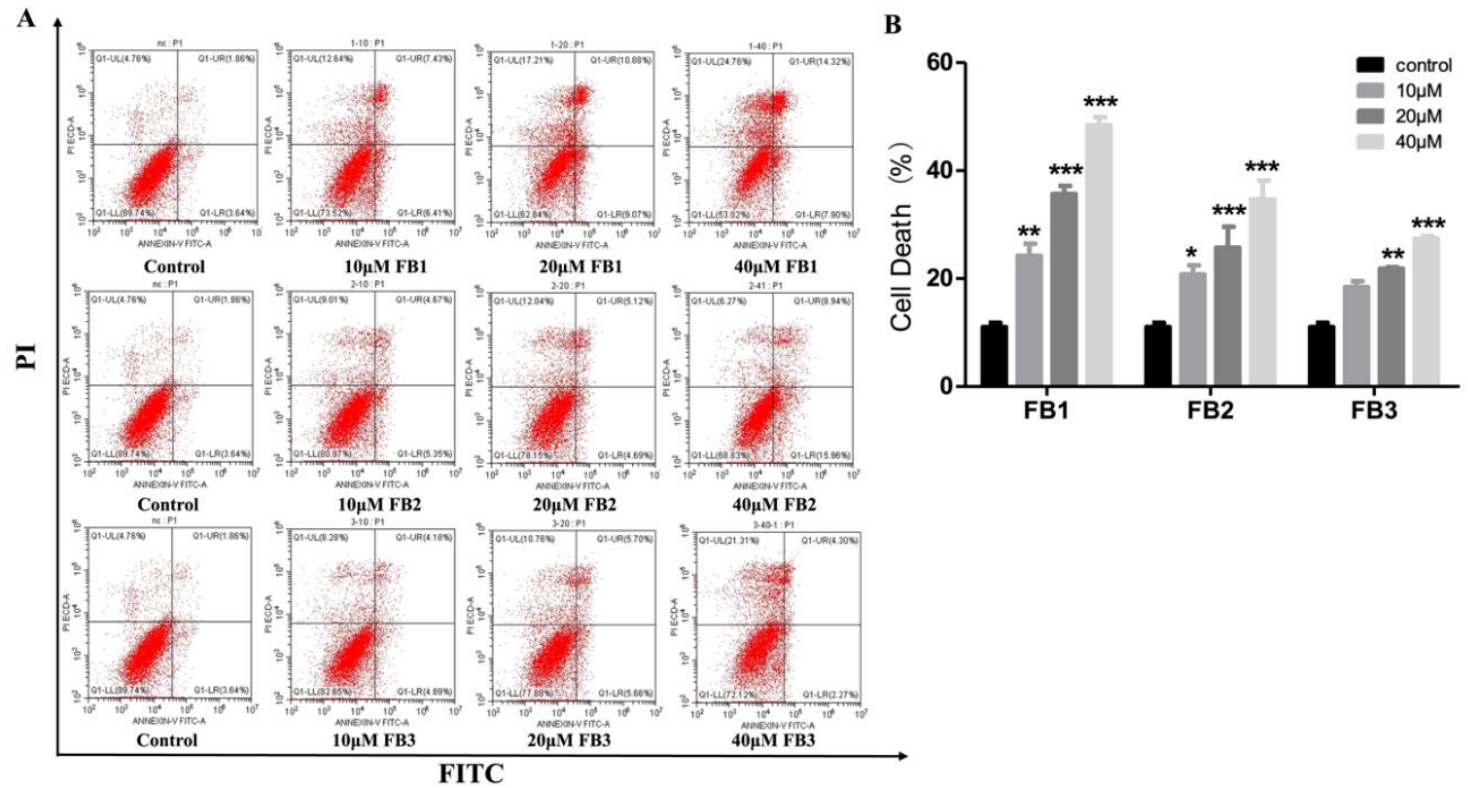

Figure 3. FB1-induced cell death in GES-1 cells. (A) Dead cells were marked with Annexin V-FITC/PI dye. The GES-1 cell death rate was analyzed by flow cytometry. (B) These data represented the mean \pm SEM of the three individual experiments $\left({ }^{*} p<0.05,{ }^{* *} p<0.01,{ }^{* * *} p<0.001\right.$, analysis of variance (ANOVA) test).

\subsection{FBs Induced ER Stress in GES-1 Cells}

It is well known that the endoplasmic reticulum (ER) stress is activated and induces cell death when the cells are threatened by the external environment [34]. Our previous study has shown that FB1 can induce ER stress in GES-1 cells [10]. We verified whether FB2 and FB3 caused ER stress in GES-1 cells. ER stress biomarkers, protein kinase R-like ER kinase (PERK), glucose regulatory protein 78 (Bip), activated transcription factor 4 (ATF4) and C/EBP homologous protein (CHOP), were detected. The immunoblotting results showed that PERK, Bip, ATF4, and CHOP levels were significantly increased after the treatment with $20 \mu \mathrm{M}$ FB1 for $48 \mathrm{~h}$ (Figure 4A). In addition, the mRNA expression level was also significantly up-regulated (Figure 4B). These results indicated that FB1 can induce ER stress in GES-1 cells significantly. For FB2 and FB3, the expression levels of ER stress markers were also increased. However, they had lower capability. The toxicity order was FB1 > FB2 >> FB3.

A

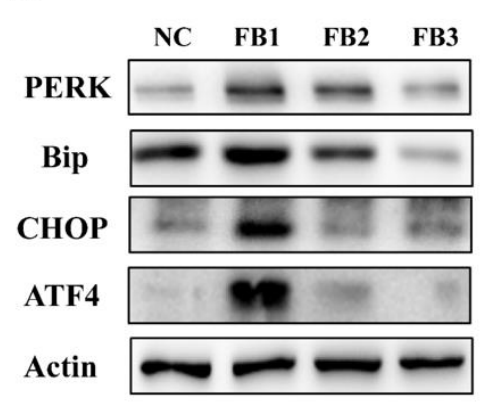

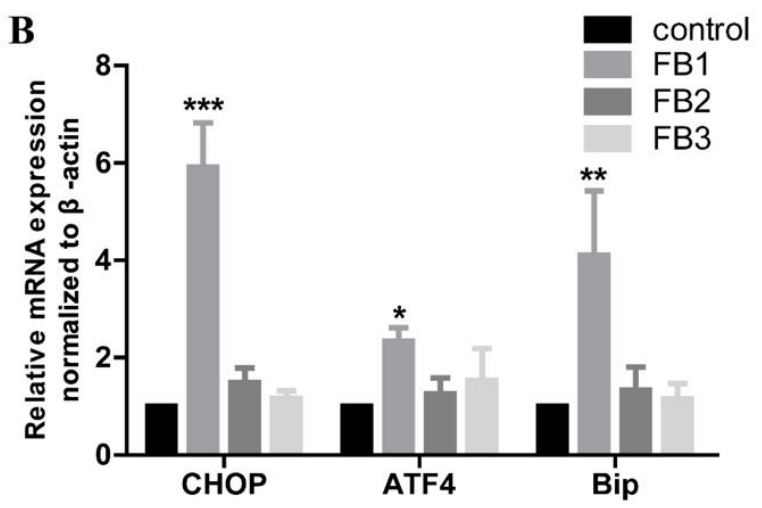

Figure 4. FBs induced ER stress in the GES-1 cells. The levels of ER stress markers were determined by immunoblotting (A) and real-time PCR (B) after treatment with $20 \mu \mathrm{M}$ FBs for $48 \mathrm{~h}$. The data represented the mean \pm SEM of the three individual experiments $\left(^{*} p<0.05,{ }^{* *} p<0.01,{ }^{* * *} p<0.001\right.$, analysis of variance (ANOVA) test). 


\subsection{Combined Toxicity of FB1, FB2 and FB3 in GES-1 Cells}

The cell viability of the dose-effect relationship curve for the toxicity of the tested mixture was shown in Figure 5. In the fumonisin B combination, the concentrations shown on the abscissa are: FB1 $(1.25-20 \mu \mathrm{M})$, FB2 $(1.25-20 \mu \mathrm{M})$ and FB3 $(2.5-40 \mu \mathrm{M})$. The results showed that the cell viability of the binary combinations remarkedly decreased. The cell viability decreased in a dose-dependent manner in the binary combinations (FB1 + FB2, FB1 + FB3). In particular, the binary combination $(20 \mu \mathrm{M}$ FB1 $+20 \mu \mathrm{M}$ FB2) were effective in reducing the cell viability compared to other mycotoxin mixtures. However, in the binary and tertiary combinations (FB2 + FB3, FB1 + FB3 + FB3), there was an upward trend in the cell activity at high concentrations, which also suggested antagonistic effects at high concentrations. At a high concentration of $20 \mu \mathrm{M}$ FB1 $+20 \mu \mathrm{M}$ FB2 $+40 \mu \mathrm{M}$ FB3, the cell survival rate decreased to approximately $64.32 \%$.

A

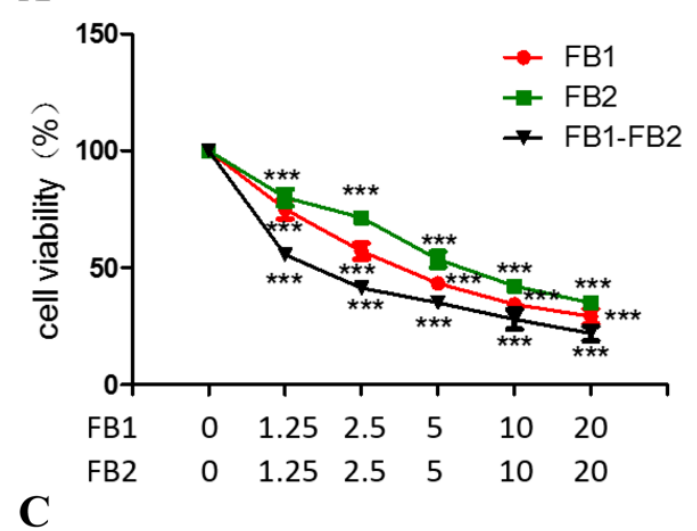

C

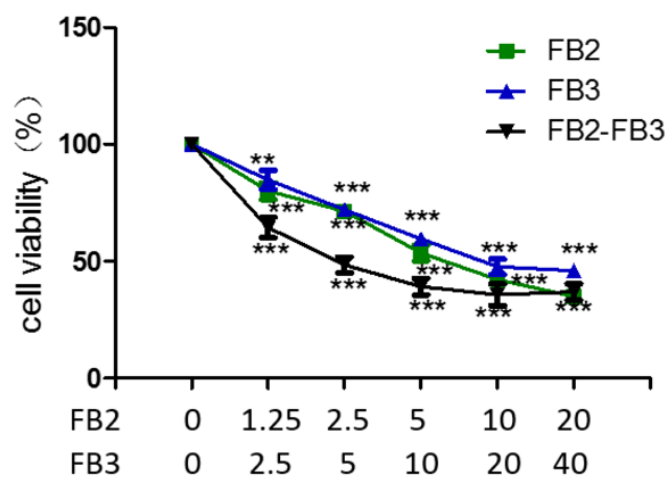

B
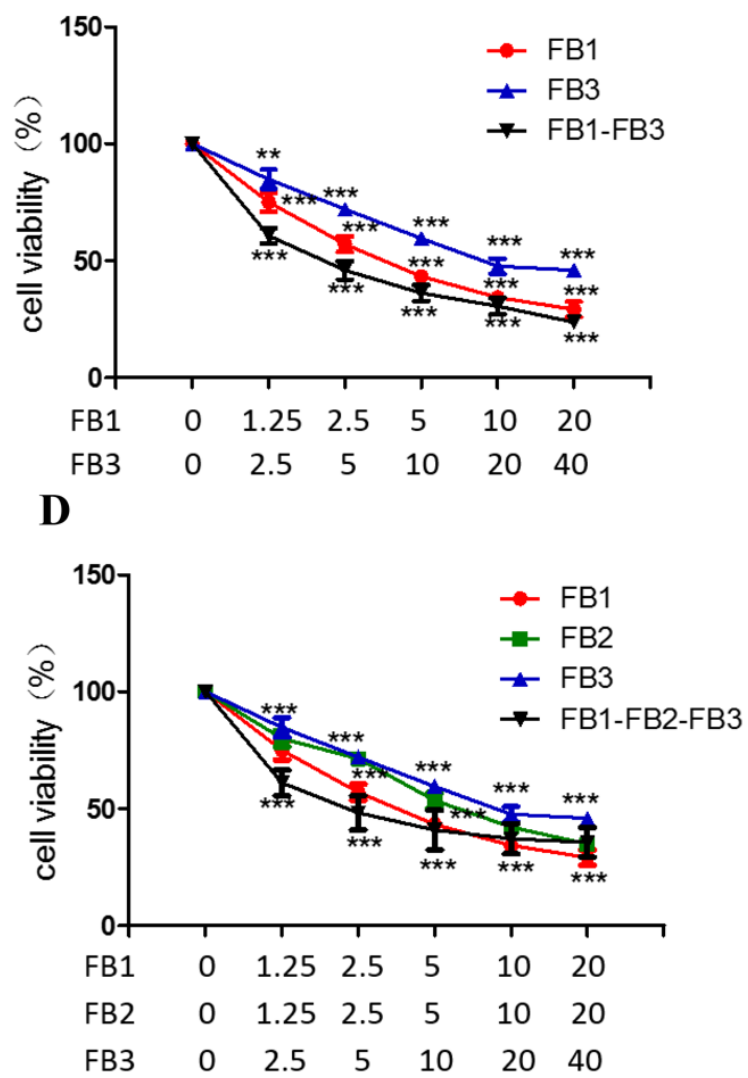

Figure 5. Interactive effects of FB1, FB2 and FB3 on the GES-1 cell viability. (A-D) GES-1 cells were treated with fumonisin alone or their mixtures for $48 \mathrm{~h}$. The data represented the mean \pm SEM of the three individual experiments $\left(* * p<0.01,{ }^{* * *} p<0.001\right.$, analysis of variance (ANOVA) test).

Table 1 presented the results of the dose-response relationship parameters obtained from in vitro cell viability studies. The correlation coefficient $(r)$ was obtained from the median-effect diagram. This showed a linear correlation coefficient, which meant it was eligible and acceptable for further data analysis using the effect equation. The results showed that the half inhibitory concentration (IC50) value was $1.59 \sim 22.43 \mu \mathrm{M}$ in binary and tertiary combinations by the isobologram method. 
Table 1. Dose-effect relationship parameters for cytotoxicity by fumonisins in GES-1 cells.

\begin{tabular}{cccc}
\hline & Dm & M & r \\
\hline FB1 & 4.43919 & -0.70722 & 0.97471 \\
FB2 & 7.45614 & -0.75675 & 0.98928 \\
FB3 & 22.43032 & -0.69375 & 0.96569 \\
FB1 + FB2 & 1.59058 & -0.51736 & 0.99049 \\
FB1 + FB3 & 4.39135 & -0.566 & 0.98716 \\
FB2 + FB3 & 5.972 & -0.40263 & 0.95451 \\
FB1 + FB2 + FB3 & 5.46792 & -0.36484 & 0.94273 \\
\hline
\end{tabular}

Dm, the median-effect dose; $m$, the slope of median-effect curves; $r$, the correlation coefficient.

The interaction effect of toxin mixtures mainly include three main different effects: synergistic, additive, and antagonistic. The types of interactions were detemined by the combination index (CI) values that were calculated by the isobologram method $[35,36]$. The CI of different cytotoxicity levels (IC10-IC75) was shown in Table 2. The results showed that the mixtures of FB1 + FB2 and FB1 + FB3 almost produced synergistic cytotoxicity against GES-1 cells at any level (IC10-IC75). In addition, at the IC10-IC50 level, the FB2 + FB3 combined exposure also had a synergistic effect. At the low cell inhibition level (IC10-IC25), the FB1 + FB2 + FB3 combination produced a synergistic effect and an antagonistic effect at the high cytotoxicity level.

Table 2. Combination index (CI) for cytotoxicity by individual fumonisins and their mixtures in GES-1 cells.

\begin{tabular}{cccccc}
\hline \multirow{2}{*}{ Mycotoxin } & \multirow{2}{*}{$\begin{array}{c}\text { Combination } \\
\text { Ratio }\end{array}$} & IC10 & IC25 & IC50 & IC75 \\
\cline { 3 - 6 } & $1: 1$ & 0.17 & 0.31 & 0.57 & 1.05 \\
\hline FB1:FB2 & $1: 2$ & 0.30 & 0.46 & 0.69 & 1.04 \\
FB1:FB3 & $1: 2$ & 0.06 & 0.20 & 0.66 & 2.27 \\
FB2:FB3 & $1: 1: 2$ & 0.06 & 0.28 & 1.23 & 5.41 \\
FB1:FB2:FB3 & &
\end{tabular}

IC, inhibitory concentration; $\mathrm{CI}<1$, indicates synergistic effects; $\mathrm{CI}=1$, indicates additive effects and $\mathrm{CI}>1$ indicates antagonistic effects.

\subsection{Disruption of Sphingolipid Metabolism Contributes to FBs Cytotoxicity}

Our previous studies have shown that the disruption of sphingolipid metabolism by the inhibition of the ceramide synthase leading to the accumulation of intracellular free sphingoid bases plays an important role in FB1-induced GES-1 cytotoxicity [10]. We then examined whether the disruption of a sphingolipid metabolism also plays an important role in the GES-1 cytotoxicity induced by FB2 and FB3. Myriocin (ISP-1) was an effective specific inhibitor of serine palmityltransferase (SPT), the first enzyme in the sphingomyelin biosynthesis pathway, which prevents the accumulation of sphingoid bases [37]. We measured the cell viability in the presence of myriocin (ISP-1) to evaluate the role of sphingolipid metabolism disorder in FB-induced cytotoxicity. As shown in Figure 6, ISP-1 alleviated the cytotoxicity induced by FBs to varying degrees. This suggested that abnormalities in the sphingolipid metabolism play a key role in the cytotoxicity induced by FB family mycotoxins. 

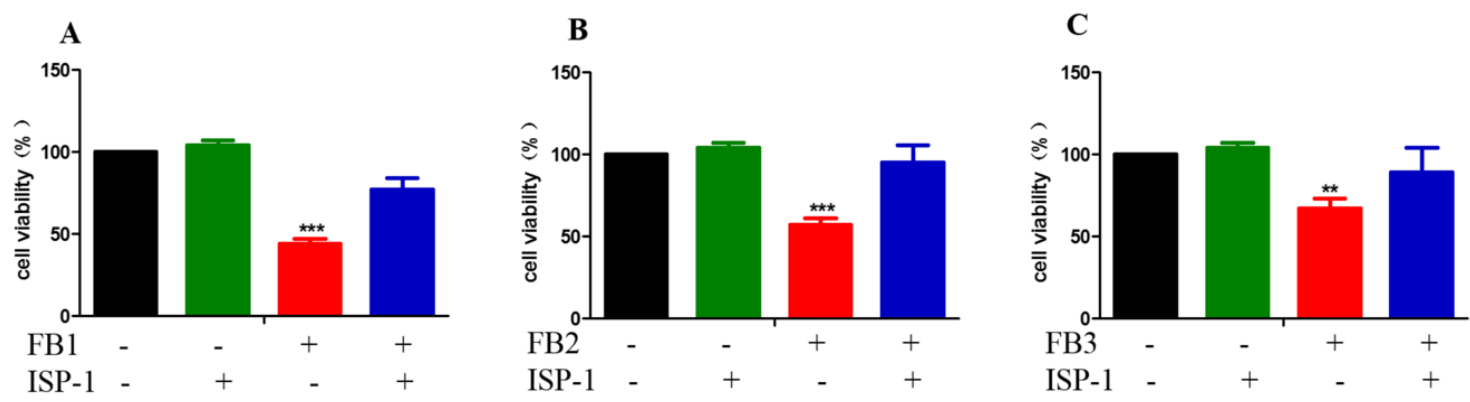

Figure 6. Myriocin (ISP-1) alleviated FB-induced GES-1 cytotoxicity. (A) Effect of ISP-1 on FB1-induced cytotoxicity. (B) Effect of ISP-1 on FB2-induced cytotoxicity. (C) Effect of ISP-1 on FB3 induced cytotoxicity. The data represented the mean \pm SEM of the three individual experiments $\left({ }^{* *} p<0.01\right.$, *** $p<0.001$, analysis of variance (ANOVA) test).

\section{Discussion}

Fumonisins often co-occur in food and feed, in different degrees all over the world. However, toxicological studies often focused on FB1, and there are a few studies on FB2 and FB3. FB1 could cause equine leucoencephalomalacia, pulmonary edema in pig, liver and kidney tumors in rodents, and be associated with esophageal cancer and neural tube defect in humans $[15,19,20,23,38]$. Nowadays, the formulation of food safety regulations and limit standards about fumonisin only referred to the toxicity data of FB1. This means we ignored the interaction between fumonisins, which can lead to inaccurate safety risk assessments [39]. The gastrointestinal tract, as the first exposure and accumulation location of toxins, is often vulnerable to mycotoxins [40]. Numerous studies have shown that mycotoxins can induce gastrointestinal injury, and FB1 can inhibit the proliferation of Caco-2 and pig intestinal epithelial cells (PIEC) cells [41-44]. Due to the increasingly restricted regulations on using animals and ensuring their welfare, cell-based systems are more favorable and applicable for toxicity evaluations. The GES-1 cells were used as an in vitro model to evaluate the risk ranking and combination toxicity of FBs in our study.

In order to provide a reliable basis for the investigation of the cytotoxic effects of toxin mixtures, it is first necessary to assess the individual effects of toxins [45]. Initially, we evaluated the effects of FBs on GES-1 cells in many different ways. These were important indexes to evaluate the toxicity of fumonisin in many studies $[10,22,46]$. Our data showed that FBs could markedly inhibit cell proliferation and increase cell membrane permeability, cell mortality, and the expression level of ER stress markers in varying degrees. The main form of cell death was necrosis. The reason may be that fumonisin, as an exogenous chemical harmful substance, causes pathological damage to GES-1 cells, leading to necrosis, which also indicates that the toxicity induced by fumonisin is irreversible. FB1-induced changes in all aspects were significantly higher than FB2 and FB3, and FB2 was also greater than FB3. Their security risk ranking was FB1 > FB2 >> FB3. FB1, FB2 and FB3 often contaminate both food and feed. Nevertheless, studies on the combined toxicity of fumonisin mixtures are lacking. This study is the first one focused on the combination toxicity of fumonisin. The combination of FB1 + FB2 and FB1 + FB3 almost produced synergistic cytotoxicity against GES-1 cells in all groups. However, the amalgam of FB2 + FB3 and three fumonisins have a synergistic effect at a low dose and an antagonistic effect at a high dose. Similar phenomena have been found in previous studies. Yang et al. found that when deoxynivalenol (DON) family mycotoxins were mixed, their interactions showed a synergistic effect at low concentration and an antagonistic effect at a high concentration [24]. A similar result was shown in v79 cells treated with citrinin and ochratoxin A mixture [47]. Although the respective toxicity of FB2 and FB3 was relatively weak, the toxicity of FB1 would be significantly affected when they were mixed with FB1. The reason may be that the cells stimulated by multiple toxins at the same time change the process of absorption, degradation, accumulation and metabolism of the original single toxin $[48,49]$. If the interaction of mycotoxin mixtures were not considered in 
the formulation of safety regulations and limit standards, its safety risk will be underestimated or overestimated, and both could result in a serious health hazard and a lot of economic losses [50,51]. This is a new viewpoint to consider the synergistic and antagonistic effects of fumonisin mixtures in future risk assessment.

Because FB1 has a similar structure to sphingosine, it can impede sphingolipid metabolism by inhibiting ceramide synthase, leading to the accumulation of free sphingoid bases in cells. This accumulation is thought to play a key role in the toxicity of FB1 [52]. Our previous study has shown that the disruption of sphingolipid metabolism is important for FB1-induced GES-1 cytotoxicity. Since the aminopentol backbone and tricarboxylic acid group (-TCA) were present in all FB structures, some reports have shown that FB2 and FB3 can also inhibit ceramide synthase in mice liver [53]. Therefore, we assessed whether the disruption of sphingolipid metabolism also plays a decisive role in FB2- and FB3-induced GES-1 cytotoxicity. We found that ISP-1 could alleviate the cytotoxicity induced by FBs in GES-1 cell and even enable to recover it to the same level as the control group in the FB2 treated group. This also proved that the disruption of sphingolipid metabolism plays an important role in FB-induced toxicity. A previous study reported that the inhibitory ability of FB2 and FB3 to ceramide synthase was lower than FB1, perhaps it is because of their differences in spatial structure [53], this may provide an explanation for the difference in FB toxicity. In the future, researchers might use ISP-1 to treat FB-induced toxicity. This also suggests that similar toxigenic molecular mechanisms are involved in the same class of toxic substances. When we study an unknown toxin, toxicity can be inferred from those toxins which have similar chemical structure and well known toxicity in the future.

\section{Materials and Methods}

\subsection{Chemicals}

Fumonisin B1 (ab142433), fumonisin B2 (ab142434) were from Abcam (Cambridge, MA, USA). Fumonisin B3 (20434) was from Cayman (Ann Arbor, MA, USA). A Cell Counting Kit-8 (CCK-8) (CK04-3000T) and Cytotoxicity Lactic Dehydrogenase (LDH) assay kit (CK12-100T) were obtained from DOJINDO Laboratories (Kumamoto, Japan). Dulbecco's modified Eagle medium with high glucose (H-DMEM) (SH30243.01) was purchased from HyClone (South Logan, UT, USA). Penicillin-streptomycin-amphotericin B solution (03-033-1B) and trypsin ethylene diamine tetraacetic acid (EDTA) Solution A (0.25\%) (03-050-1B) were purchased from BioInd (Kibbutz Beit, Israel). Annexin V-FITC Apoptosis Detection Kit I (556547) was purchased from BD Pharmingen (San Diego, CA, USA). Myriocin (ISP-1) (476300-5MG) was from Merck/Millipore (Billerica, MA, USA). The fetal bovine serum (10099141C) and TRIzol reagent (15596018) were obtained from Invitrogen (Waltham, MA, USA). PrimeScript ${ }^{\mathrm{TM}}$ RT Master Mix (RR036A) and SYBR ${ }^{\circledR}$ Premix Ex Taq ${ }^{\mathrm{TM}}$ II (RR820A) were from Takara Biomedical Technology (Beijing, China). The bicinchoninic acid assay kit (20201ES90) was purchased from YEASEN Biotechnology (Shanghai, China). The NC membrane (FFN02) was from Beyotime Biotech (Nantong, China). The primary antibodies used for the immunoblotting analyses against Bip (3177S), ATF4 (11815S), PERK (5683S), CHOP (2895S), Actin (3700S) and the secondary antibody IgG labeled with horseradish peroxidase (7076S and 7074S) were purchased from Cell Signalling Technology (Danvers, MA, USA).

\subsection{Cell Culture and Treatments}

The human gastric epithelial cell line (GES-1) was obtained from Beijing Beina Chuanglian Biotechnology Institute (Beijing, China). The GES-1 cells were cultured in H-DMEM (HyClone) with $10 \%$ fetal bovine serum (Invitrogen) and penicillin-streptomycin-amphotericin B (BioInd). When the cells were $60-70 \%$, the cells were treated with FBs and/or other agents. 


\subsection{Cell viability Assay and Membrane Leakage Assay}

Ten thousand cells were added to each well of the 96-well plate. After $24 \mathrm{~h}$, the culture medium was changed to a $100 \mu \mathrm{L}$ medium with or without fumonisin. Further training after $48 \mathrm{~h}$, cell viability and membrane leakage were detected. Cell viability and membrane leakage were measured according to the manufacturer's instructions using a Cell Counting Kit-8 (DOJINDO) and a Cytotoxicity LDH assay kit (DOJINDO), respectively. The results were representative of three independent experiments. Absorbance was recorded with Tecan GENios Pro tablet reader (Tecan).

\subsection{Cell Death Analysis}

Cell death was detected by flow cytometry using an Annexin V-FITC Apoptosis Detection Kit I (BD Pharmingen). The GES-1 cells were treated with FBs $(0-40 \mu \mathrm{M})$ for $48 \mathrm{~h}$, then they were digested $0.25 \%$ trypsin (BioInd) and harvested by centrifugation (1000 rpm/min for $5 \mathrm{~min}$ ). The cells were stained with $5 \mu \mathrm{L}$ PI and $5 \mu \mathrm{L}$ Annexin V-FITC (BD Pharmingen) in $100 \mu \mathrm{L}$ buffer. The cells were examined by Beckman CytoFlex S (Beckman), and the data were analyzed by the machine's own analysis software.

\subsection{Immunoblotting}

The cells were treated with FBs for $48 \mathrm{~h}$, then washed once with phosphate buffered saline and harvested. The harvested cells were lysed for $30 \mathrm{~min}$ and rotated at $13,000 \mathrm{rpm} / \mathrm{min}$ for $20 \mathrm{~min}$ at $4{ }^{\circ} \mathrm{C}$. The soluble portion was gathered and the protein concentration was determined by a bicinchoninic acid assay (YEASEN Biotechnology). Then, the $15 \mu \mathrm{L}$ protein samples (the protein content of each sample was the same) and pre-stained molecular weight markers were subjected to $10 \%$ or $12.5 \%$ sodium dodecyl sulfate-polyacrylamide gel electrophoresis (this gel had 15 lanes) and transferred to NC membranes (Beyotime Biotech) by electroblotting at $4{ }^{\circ} \mathrm{C}$. Subsequently, the membranes were sealed with 10\% skimmed milk powder in Tris-buffered saline and Tween 20 for $2 \mathrm{~h}$ at room temperature and incubated overnight in specific antibodies (Actin, ATF4, CHOP, Bip and PERK) (Cell Signalling Technology) diluted 1:1000 or 1:2000 at $4{ }^{\circ} \mathrm{C}$. The secondary antibody IgG was labeled with horseradish peroxidase (Cell Signalling Technology), diluted to 1:2000, and incubated with the membrane at room temperature for $2 \mathrm{~h}$. The staining protein was shown by the Tanon-5200Multi electroluminescence detection system (Tanon).

\subsection{Real-Time PCR}

The total RNA of the GES-1 cells was prepared using TRIzol reagent (Invitrogen). The cDNA was synthesized using PrimeScript ${ }^{\mathrm{TM}} \mathrm{RT}$ Master Mix (Takara). Each sample was quantified using SYBR ${ }^{\circledR}$ Premix Ex Taq ${ }^{\mathrm{TM}} \mathrm{II}$ (Takara). The primer sequence and additional information were shown in Table S1. The CT value was detected through StepOnePlus ${ }^{\mathrm{TM}}$ Real-Time PCR System (Applied Biosystems ${ }^{\mathrm{TM}}$ ). The gene expression level was analyzed by $\mathrm{CT}$ comparison. The expression level of each gene was normalized to the expression level of actin by standard curve method.

\subsection{Statistical Analysis}

The data shown in the study represented the mean \pm SEM of the three independent experiments. Tukey or post hoc Bonferroni test after the event was used for one-way or two-way ANOVA, and GraphPad Prism 5 (GraphPad Software Inc., San Diego, CA, USA) was used to evaluate the progressive changes among groups. All the probabilities were two-sided, and $p<0.05$ was considered statistically significant. All the parameters about combined toxicity were calculated through using the Compusyn software package (ComboSyn Inc., Paramus, NJ, USA, http://www.combosyn.com/, 12/11/2018); for instance, the dose of median-effect (Dm), the slope of the median effect curves (m), the coefficient of linear correlation and the combination index (CI). All methods were carried out in accordance with relevant guidelines and regulations. 


\section{Conclusions}

In this study, GES-1 cells were used as in vitro model to evaluate the toxicity of FB1, FB2 and FB3. We found that they could significantly reduce the cell viability, increase membrane leakage, cell death and induce ER stress. We confirmed that their toxicity potency was FB1 > FB2 >> FB3. With the widespread study of fumonisin mixtures on GES-1 cells, the interactions amongst them lead to synergistic or antagonistic effects. We also found that myriocin (ISP-1) could alleviate the cytotoxicity induced by FBs in GES-1 cell. These data implied that FBs could cause gastrointestinal damage through inducing sphingolipid metabolism disorder and activating ER stress. Finally, this study helps to determine or optimize the legal limits of mycotoxins in food and feed. Particularly, more attention should be focused on the toxins with synergistic effect at low concentration. We also provide a method to intervene in the FBs toxicity. In the future, we will explore the molecular mechanisms of the synergistic and antagonistic effects between them.

Supplementary Materials: Can be found at http://www.mdpi.com/1422-0067/21/16/5917/s1. Table S1. RT-PCR primers for the ER stress genes.

Author Contributions: Conceptualization, A.W. and S.Y; methodology, S.Y.; software, S.Y. and B.J.; validation, S.Y.; formal analysis, S.Y.; investigation, S.Y. and B.J.; writing—original draft preparation, A.W. and S.Y.; writing一review and editing, A.W., S.Y., D.Y. and N.L.; funding acquisition, A.W. All authors have read and agreed to the published version of the manuscript.

Funding: This research was funded by the National Key Research and Development Program of China (2017YFC1600304), National Natural Science Foundation of China (31772087), Science and Technology Service Network Initiative, CAS (KFJ-STS-ZDTP-084), Shanghai Agriculture Applied Technology Development Program, China (2019-02-08-00-02-F01145) and Biological agriculture project of Shanghai Science and Technology Commission (17391901300).

Conflicts of Interest: The authors declare no conflict of interest.

\section{Abbreviations}

$\begin{array}{ll}\text { FBs } & \text { Fumonisin Bs } \\ \text { FB1 } & \text { Fumonisin B1 } \\ \text { FB2 } & \text { Fumonisin B2 } \\ \text { FB3 } & \text { Fumonisin B3 } \\ \text { CCK-8 } & \text { Cell Counting Kit-8 } \\ \text { LDH } & \text { lactic dehydrogenase } \\ \text { Annexin V-FITC/PI } & \text { Annexin V-fluoresceine isothiocyanate/propidium iodide } \\ \text { ER } & \text { Endoplasmic reticulum } \\ \text { EDTA } & \text { Ethylene diamine tetraacetic acid } \\ \text { PERK } & \text { Protein kinase R-like ER kinase } \\ \text { CHOP } & \text { C/EBP homologous protein } \\ \text { Bip } & \text { Glucose-regulated protein 78 } \\ \text { ATF4 } & \text { Activating transcription factor } 4 \\ \text { GES-1 } & \text { Human gastric epithelial cell line } \\ \text { H-DMEM } & \text { Dulbecco's modified eagle medium with high glucose } \\ \text { GIT } & \text { Gastrointestinal tract } \\ \text { SPT } & \text { Serine palmitoyltransferase } \\ \text { PIEC } & \text { Pig intestinal epithelial cells } \\ \text { ISP-1 } & \text { Myriocin } \\ \text { IC } & \text { Inhibitory concentration } \\ \text { CI } & \text { Combination index } \\ \text { DON } & \text { Deoxynivalenol } \\ \end{array}$




\section{References}

1. Edite Bezerra da Rocha, M.; Freire, F.d.C.O.; Erlan Feitosa Maia, F.; Izabel Florindo Guedes, M.; Rondina, D. Mycotoxins and their effects on human and animal health. Food Control 2014, 36, 159-165. [CrossRef]

2. Mousavi Khaneghah, A.; Fakhri, Y.; Gahruie, H.H.; Niakousari, M.; Sant'Ana, A.S. Mycotoxins in cereal-based products during 24 years (1983-2017): A global systematic review. Trends Food Sci. Technol. 2019, 91, 95-105. [CrossRef]

3. Yazar, S.; Omurtag, G.Z. Fumonisins, trichothecenes and zearalenone in cereals. Int. J. Mol. Sci. 2008, 9, 2062-2090. [CrossRef] [PubMed]

4. Wan, L.Y.; Turner, P.C.; El-Nezami, H. Individual and combined cytotoxic effects of Fusarium toxins (deoxynivalenol, nivalenol, zearalenone and fumonisins B1) on swine jejunal epithelial cells. Food Chem. Toxicol. 2013, 57, 276-283. [CrossRef]

5. Zhou, D.; Wang, X.; Chen, G.; Sun, S.; Yang, Y.; Zhu, Z.; Duan, C. The Major Fusarium Species Causing Maize Ear and Kernel Rot and Their Toxigenicity in Chongqing, China. Toxins 2018, 10, 90. [CrossRef]

6. Cao, A.; Santiago, R.; Ramos, A.J.; Souto, X.C.; Aguin, O.; Malvar, R.A.; Butron, A. Critical environmental and genotypic factors for Fusarium verticillioides infection, fungal growth and fumonisin contamination in maize grown in northwestern Spain. Int. J. Food Microbiol. 2014, 177, 63-71. [CrossRef]

7. Esposito, F.; Fasano, E.; Scognamiglio, G.; Nardone, A.; Triassi, M.; Cirillo, T. Exposure assessment to fumonisins B1, B2 and B3 through consumption of gluten-free foodstuffs intended for people affected by celiac disease. Food Chem. Toxicol. 2016, 97, 395-401. [CrossRef]

8. Waśkiewicz, A.; Beszterda, M.; Goliński, P. Occurrence of fumonisins in food-An interdisciplinary approach to the problem. Food Control 2012, 26, 491-499. [CrossRef]

9. Gazzotti, T.; Zironi, E.; Lugoboni, B.; Barbarossa, A.; Piva, A.; Pagliuca, G. Analysis of fumonisins B1, B2 and their hydrolysed metabolites in pig liver by LC-MS/MS. Food Chem. 2011, 125, 1379-1384. [CrossRef]

10. Yu, S.; Jia, B.; Yang, Y.; Liu, N.; Wu, A. Involvement of PERK-CHOP pathway in fumonisin B1- induced cytotoxicity in human gastric epithelial cells. Food Chem. Toxicol. 2020, 136, 111080. [CrossRef]

11. Kim, D.H.; Lee, I.H.; Do, W.H.; Nam, W.S.; Li, H.; Jang, H.S.; Lee, C. Incidence and levels of deoxynivalenol, fumonisins and zearalenone contaminants in animal feeds used in Korea in 2012. Toxins 2013, 6, $20-32$. [CrossRef] [PubMed]

12. Li, F.; Jiang, D.; Zheng, F.; Chen, J.; Li, W. Fumonisins B(1), B(2) and B(3) in corn products, wheat flour and corn oil marketed in Shandong province of China. Food Addit. Contam. Part B Surveill 2015, 8, 169-174. [CrossRef] [PubMed]

13. Hartinger, D.; Moll, W. Fumonisin elimination and prospects for detoxification by enzymatic transformation. World Mycotoxin J. 2011, 4, 271-283. [CrossRef]

14. Maenetje, P.W.; De Villiers, N.; Dutton, M.F. The use of isolated human lymphocytes in mycotoxin cytotoxicity testing. Int. J. Mol. Sci. 2008, 9, 1515-1526. [CrossRef]

15. Wang, J.; Zhou, Y.; Liu, W.; Zhu, X.; Du, L.; Wang, Q. Fumonisin level in corn-based food and feed from Linxian County, a high-risk area for esophageal cancer in china. Food Chem. 2008, 106, 241-246. [CrossRef]

16. Regnier, M.; Polizzi, A.; Lukowicz, C.; Smati, S.; Lasserre, F.; Lippi, Y.; Naylies, C.; Laffitte, J.; Betoulieres, C.; Montagner, A.; et al. The protective role of liver X receptor (LXR) during fumonisin B1-induced hepatotoxicity. Arch. Toxicol. 2019, 93, 505-517. [CrossRef]

17. Szabo, A.; Szabo-Fodor, J.; Kachlek, M.; Mezes, M.; Balogh, K.; Glavits, R.; Ali, O.; Zeebone, Y.Y.; Kovacs, M. Dose and Exposure Time-Dependent Renal and Hepatic Effects of Intraperitoneally Administered Fumonisin B(1) in Rats. Toxins 2018, 10, 465. [CrossRef]

18. Yuan, Q.; Jiang, Y.; Fan, Y.; Ma, Y.; Lei, H.; Su, J. Fumonisin B1 Induces Oxidative Stress and Breaks Barrier Functions in Pig Iliac Endothelium Cells. Toxins 2019, 11, 387. [CrossRef]

19. Muller, S.; Dekant, W.; Mally, A. Fumonisin B1 and the kidney: Modes of action for renal tumor formation by fumonisin B1 in rodents. Food Chem. Toxicol. 2012, 50, 3833-3846. [CrossRef]

20. Liu, X.; Fan, L.; Yin, S.; Chen, H.; Hu, H. Molecular mechanisms of fumonisin B1-induced toxicities and its applications in the mechanism-based interventions. Toxicon 2019, 167, 1-5. [CrossRef]

21. Van der Westhuizen, L.; Shephard, G.S.; Rheeder, J.P.; Burger, H.M. Individual fumonisin exposure and sphingoid base levels in rural populations consuming maize in South Africa. Food Chem. Toxicol. 2010, 48, 1698-1703. [CrossRef] [PubMed] 
22. Yin, S.; Guo, X.; Li, J.; Fan, L.; Hu, H. Fumonisin B1 induces autophagic cell death via activation of ERN1-MAPK8/9/10 pathway in monkey kidney MARC-145 cells. Arch. Toxicol. 2016, 90, 985-996. [CrossRef] [PubMed]

23. Direito, G.M.; Almeida, A.P.; Aquino, S.; Dos Reis, T.A.; Pozzi, C.R.; Correa, B. Evaluation of sphingolipids in Wistar rats treated to prolonged and single oral doses of fumonisin b(1). Int. J. Mol. Sci. 2009, 10, 50-61. [CrossRef] [PubMed]

24. Yang, Y.; Yu, S.; Tan, Y.; Liu, N.; Wu, A. Individual and Combined Cytotoxic Effects of Co-Occurring Deoxynivalenol Family Mycotoxins on Human Gastric Epithelial Cells. Toxins 2017, 9, 96. [CrossRef]

25. Zhang, W.; Zhang, S.; Zhang, M.; Yang, L.; Cheng, B.; Li, J.; Shan, A. Individual and combined effects of Fusarium toxins on apoptosis in PK15 cells and the protective role of $\mathrm{N}$-acetylcysteine. Food Chem. Toxicol. 2018, 111, 27-43. [CrossRef]

26. Xue, K.S.; Qian, G.; Lin, S.; Su, J.; Tang, L.; Gelderblom, W.C.A.; Riley, R.T.; Phillips, T.D.; Wang, J.S. Modulation of pre-neoplastic biomarkers induced by sequential aflatoxin B1 and fumonisin B1 exposure in F344 rats treated with UPSN clay. Food Chem. Toxicol. 2018, 114, 316-324. [CrossRef]

27. Li, R.; Tao, B.; Pang, M.; Liu, Y.; Dong, J. Natural occurrence of fumonisins B1 and B2 in maize from three main maize-producing provinces in China. Food Control 2015, 50, 838-842. [CrossRef]

28. Bryła, M.; Roszko, M.; Szymczyk, K.; Jędrzejczak, R.; Obiedziński, M.W. Fumonisins and their masked forms in maize products. Food Control 2016, 59, 619-627. [CrossRef]

29. Hahn, I.; Nagl, V.; Schwartz-Zimmermann, H.E.; Varga, E.; Schwarz, C.; Slavik, V.; Reisinger, N.; Malachova, A.; Cirlini, M.; Generotti, S.; et al. Effects of orally administered fumonisin B(1) (FB(1)), partially hydrolysed $\mathrm{FB}(1)$, hydrolysed $\mathrm{FB}(1)$ and $\mathrm{N}-(1-$ deoxy-D-fructos-1-yl) $\mathrm{FB}(1)$ on the sphingolipid metabolism in rats. Food Chem. Toxicol. 2015, 76, 11-18. [CrossRef]

30. Yang, Y.; Yu, S.; Liu, N.; Xu, H.; Gong, Y.; Wu, Y.; Wang, P.; Su, X.; Liao, Y.; De Saeger, S.; et al. Transcription Factor FOXO3a Is a Negative Regulator of Cytotoxicity of Fusarium mycotoxin in GES-1 Cells. Toxicol. Sci. 2018, 166, 370-381. [CrossRef]

31. Gajecka, M.; Waskiewicz, A.; Zielonka, L.; Golinski, P.; Rykaczewska, A.; Lisieska-Zolnierczyk, S.; Gajecki, M.T. Mycotoxin levels in the digestive tissues of immature gilts exposed to zearalenone and deoxynivalenol. Toxicon 2018, 153, 1-11. [CrossRef] [PubMed]

32. Antonissen, G.; Devreese, M.; De Baere, S.; Martel, A.; Van Immerseel, F.; Croubels, S. Impact of Fusarium mycotoxins on hepatic and intestinal mRNA expression of cytochrome P450 enzymes and drug transporters, and on the pharmacokinetics of oral enrofloxacin in broiler chickens. Food Chem. Toxicol. 2017, 101, 75-83. [CrossRef] [PubMed]

33. Minervini, F.; Debellis, L.; Garbetta, A.; De Girolamo, A.; Schena, R.; Portincasa, P.; Visconti, A. Influence on functional parameters of intestinal tract induced by short-term exposure to fumonisins contaminated corn chyme samples. Food Chem. Toxicol. 2014, 66, 166-172. [CrossRef] [PubMed]

34. Chen, F.; Li, Q.; Zhang, Z.; Lin, P.; Lei, L.; Wang, A.; Jin, Y. Endoplasmic Reticulum Stress Cooperates in Zearalenone-Induced Cell Death of RAW 264.7 Macrophages. Int. J. Mol. Sci. 2015, 16, 19780-19795. [CrossRef]

35. Ashton, J.C. Drug combination studies and their synergy quantification using the Chou-Talalay method-letter. Cancer Res. 2015, 75, 2400. [CrossRef]

36. Chou, T.C. Theoretical basis, experimental design, and computerized simulation of synergism and antagonism in drug combination studies. Pharmacol. Rev. 2006, 58, 621-681. [CrossRef]

37. Hojjati, M.R.; Li, Z.; Zhou, H.; Tang, S.; Huan, C.; Ooi, E.; Lu, S.; Jiang, X.C. Effect of myriocin on plasma sphingolipid metabolism and atherosclerosis in apoE-deficient mice. J. Biol. Chem. 2005, 280, 10284-10289. [CrossRef]

38. Missmer, S.A.; Suarez, L.; Felkner, M.; Wang, E.; Merrill, A.H., Jr.; Rothman, K.J.; Hendricks, K.A. Exposure to fumonisins and the occurrence of neural tube defects along the Texas-Mexico border. Environ. Health Perspect. 2006, 114, 237-241. [CrossRef]

39. Assuncao, R.; Pinhao, M.; Loureiro, S.; Alvito, P.; Silva, M.J. A multi-endpoint approach to the combined toxic effects of patulin and ochratoxin a in human intestinal cells. Toxicol. Lett. 2019, 313, 120-129. [CrossRef]

40. Sobral, M.M.C.; Faria, M.A.; Cunha, S.C.; Miladinovic, B.; Ferreira, I.M. Transport of mycotoxins across human gastric NCI-N87 and intestinal Caco-2cell models. Food Chem. Toxicol. 2019, 131, 110595. [CrossRef] 
41. Bouhet, S.; Le Dorze, E.; Peres, S.; Fairbrother, J.M.; Oswald, I.P. Mycotoxin fumonisin B1 selectively down-regulates the basal IL-8 expression in pig intestine: In vivo and in vitro studies. Food Chem. Toxicol. 2006, 44, 1768-1773. [CrossRef]

42. Gao, Y.N.; Wang, J.Q.; Li, S.L.; Zhang, Y.D.; Zheng, N. Aflatoxin M1 cytotoxicity against human intestinal Caco-2 cells is enhanced in the presence of other mycotoxins. Food Chem. Toxicol. 2016, 96, 79-89. [CrossRef]

43. Gu, M.J.; Han, S.E.; Hwang, K.; Mayer, E.; Reisinger, N.; Schatzmayr, D.; Park, B.C.; Han, S.H.; Yun, C.H. Hydrolyzed fumonisin B1 induces less inflammatory responses than fumonisin B1 in the co-culture model of porcine intestinal epithelial and immune cells. Toxicol. Lett. 2019, 305, 110-116. [CrossRef] [PubMed]

44. Ma, Y.; Zhang, A.; Shi, Z.; He, C.; Ding, J.; Wang, X.; Ma, J.; Zhang, H. A mitochondria-mediated apoptotic pathway induced by deoxynivalenol in human colon cancer cells. Toxicol. In Vitro 2012, 26, 414-420. [CrossRef] [PubMed]

45. Heussner, A.H.; Dietrich, D.R.; O’Brien, E. In vitro investigation of individual and combined cytotoxic effects of ochratoxin A and other selected mycotoxins on renal cells. Toxicol. In Vitro 2006, 20, 332-341. [CrossRef] [PubMed]

46. Khan, R.B.; Phulukdaree, A.; Chuturgoon, A.A. Fumonisin B1 induces oxidative stress in oesophageal (SNO) cancer cells. Toxicon 2018, 141, 104-111. [CrossRef]

47. Follmann, W.; Behm, C.; Degen, G.H. Toxicity of the mycotoxin citrinin and its metabolite dihydrocitrinone and of mixtures of citrinin and ochratoxin A in vitro. Arch. Toxicol. 2014, 88, 1097-1107. [CrossRef]

48. Nagata, S.; Zhou, X.; Okamura, H. Antagonistic and Synergistic Effects of Antifouling Chemicals in Mixture. Encycl. Ecol. 2008, 194-203. [CrossRef]

49. Fernández-Alba, A.R.; Hernando, M.D.; Piedra, L.; Chisti, Y. Toxicity evaluation of single and mixed antifouling biocides measured with acute toxicity bioassays. Anal. Chim. Acta 2002, 456, 303-312.

50. Smith, M.C.; Gheux, A.; Coton, M.; Madec, S.; Hymery, N.; Coton, E. In vitro co-culture models to evaluate acute cytotoxicity of individual and combined mycotoxin exposures on Caco-2, THP-1 and HepaRG human cell lines. Chem. Biol. Interact. 2018, 281, 51-59. [CrossRef]

51. Meneely, J.P.; Hajslova, J.; Krska, R.; Elliott, C.T. Assessing the combined toxicity of the natural toxins, aflatoxin B1, fumonisin B1 and microcystin-LR by high content analysis. Food Chem. Toxicol. 2018, 121, 527-540. [CrossRef] [PubMed]

52. Soriano, J.M.; Gonzalez, L.; Catala, A.I. Mechanism of action of sphingolipids and their metabolites in the toxicity of fumonisin B1. Prog. Lipid. Res. 2005, 44, 345-356. [CrossRef] [PubMed]

53. Howard, P.C.; Couch, L.H.; Patton, R.E.; Eppley, R.M.; Doerge, D.R.; Churchwell, M.I.; Marques, M.M.; Okerberg, C.V. Comparison of the toxicity of several fumonisin derivatives in a 28-day feeding study with female B6C3F(1) mice. Toxicol. Appl. Pharmacol. 2002, 185, 153-165. [CrossRef] [PubMed] 